\title{
Análisis de un soneto de Dario: hombre y poeta
}

Cetcar al hombre no es tarea fácil. Podemos definirlo, mas no a este hombre: al que tenemos delante de nosotros, nuestro prójimo. Lo "imprevisto" - conditio sine qua non est homo- rompe los moldes u hormas preparados de antemano. Lo particular resiste y no quiere quedar prendido en lo general.

Definir al poeta ofrece mayores inconvenientes. A veces, imaginamos haberlo cogido en la trampa de un concepto: cárcel racional. Surge nuestro supuesto por creer que hemos aprehendido sus diversas "obras". Terrible engaño. En primer lugar, un poema se niega a la conceptuación: rebasa el continente lógico. En segundo, cada obra tuvo su hora, $s u$ lugar y $s u$ lengua: no es posible hallarle un común denominador. La suma de las fracciones será, siempre, inexacta, porque no existen fracciones: fue un espejismo de racionalista.

Nuestro decir nace al calor de un poemita de Darío, dedicado a don Ramón del Valle Inclán. El vaso poético, que lo contiene, es reducido: un soneto. ${ }^{1}$ Los catorce versos abarcan cuatto situaciones.

1 Este gran don Ramón, de las barbas de chivo, cuya sonrisa es la flor de su figura, parece un viejo dios, altanero y esquivo que se animase en la frialdad de su escultupa.

El cobre de sus ojos por instantes fulgura y da una llama roja tras un ramo de olivo. Tengo la sensación de que siento y que vivo a su lado una vida más intensa y más dura.

Este gran don Ramón del Valle Inclán me inquieta, $y$ a traves del zodiaco de mis versos actuales se me esfuma en radiosas visiones de poeta, 
I.-el hombre: descripción [v. I a 6],

2.- -el contacto con el hombre: sensación [v. 7 a 8],

3.-el poeta: 10 buidizo $[\mathrm{V} .9$ a 12$]$,

4.-la acción pasada y traída al presente: evocación [ [V. I3 $_{3}$ a 14 ]. Recreemos cada una de ellas:

I.-De seguro que Darío tentó diversos procedimientos (en su hablar interior, previo a la creación) para reflejar, en un soneto, ${ }^{2}$ a Valle Inclán. Se trata del hombre: del hombre don Ramón. De su mano - mano poética- huía el objeto. Y el poeta halló el recurso: alojarlo en un cuadro. Al igual que un "Caballero de la mano en el pecho", un "San Jerónimo", etc., así nos aparece Valle Inclán. La estructura del primer verso,

\section{Este gran don Ramón, de las barbas de chivo,}

deja un susurro, en su extremo, extralingüístico; nuestros oídos escuchan una especie de

$$
\text { "que aqui veis"; }
$$

ha sido el único medio: meterlo en un marco, a manera de retrato. El señalador $[=e ́ s t e]$ coloca una distancia - un espacio- entre la imagen pictórica y el que narra. Prendido, así, el objeto, el narrador ${ }^{3}$ empezará a darnos señales de un hombre, metido en una circunstancia: en el cuadro.

El primer dato está montado en un andamiaje característico:

a) barbas: lo que es real,

b) de cbivo: el macho cabrío, insinuación de lo satánico.

El segundo dato, es resumidor: desde todos los extremos de su figura se acude a un lugar: a la sonrisa; por eso, flor de su figura. Unica nota de color: sobria, severa. ${ }^{4}$

Como el trazado es débil -insuficiente-, se recurre a la comparación (se mira, con el recuerdo, a otro cuadro o estatua):

o se me rompe en un fracaso de cristales.

Yo lo be visto arrancarse del pecbo la saeta

que le lanzan los siete pecados capitales.

2 El hecho de escoger el soneto, como recipiente, ya es significativo.

$3 \mathrm{El}$, tan acostumbrado a las grandes extensiones, sin límites.

4 En la sonrisa intervienen también, los ojos; por eso los cita, más abajo. 


\section{Parelce un viejo dios, altanero $y$ esquivo,}

es decir, astuto [=viejo], soberbio $[=$ altaneno $]$ y que se esconde detrás de algo, de las barbas [=esquivo]. Se inicia un movimiento hacia dentro, desde la frialdad de su escultura: tiene alma.

Con todo, no lo ha aprehendido. Pues el esquema queda reducido a la fórmula:

"este gran don Ramón. . parece un..."

El hombre don Ramón - aun en el cuadro- se escapa, y sólo la comparación, acompañada de descansillos $[=$ barbas de chivo, cuya sonrisa es $]$ puede darnos, entre objeto comparado y objeto comparante -ahí, en medio- un posible imaginar.

De pronto - un destello de luz ilumina la escena-, se detiene ante unos datos aparentes: ojos, llama roja y ramo de olivo. Se presentan por instantes, como el eruptar de un volcán. No los podemos aislar; forman un todo: es movimiento y no "cosa fijada". Ia acción es "temporal-intermitente" $[=$ por instantes fulgura $]$; es decir, se dan instantes en que no actúa: descansa [ $[=\mathrm{es,} \mathrm{entonces} \mathrm{la} \mathrm{esculturd} \mathrm{fria}]$. La misma impresión - como una amplificatio cuidadosa de los detalles-se reproduce bajo otra cobertura y con otros designios internos:

\section{da una llama roja tras un ramo de olivo.}

El fulgurar de los ojos da una llama roja $[$ =pasión: mundo-demoniocarne] que en el descansar se ve encubierta por un ramo de olivo [=la paz, el descanso]; pero no es así: la llama roja, la pasión sigue dándose. . . y casi a punto de incendiar el tamo de olivo. En lo más hondo de lo expresado están: lo "demoniaco" y lo "santo".

Hasta aquí ha podido dar señalamientos de lo que es Valle Inclán. El hombre éste ha sido cazado en un cuadro, plásticamente; pero un cuadro reproduce no el hacerse, sino un "estar" en su ahí y en su ahora, ajeno

5 Recuerdo plástico de Dario. La figura es, aquí, helénica: recuerda al Dionisos barbado.

"6 Recuerdo de esas estampas muy "comienzo de siglo", que no tienen ojos: están vaciados y detrás se les ponen "unos" que se mueven mediante la acción de la mano. Y, también, una especie de máscara o careta, tras la cual está el hombre de carne y huesos: el rostro de la máscara es rígido, con una sonrisa fija, estereotipada, mas los ojos se mueven. 
a otros; es la fijación de un momento: el estado de una serie de estados que forjan la vida de un hombre.

2.- Se ha producido un descanso en el narrar y mirar. Ahora, los ojos se dirigen a otro sitio, penetran hasta dentro del poeta y, allá, en lo hondo, se proyecta la figura del cuadro: en el espejo de la conciencia. Y se siente confortado; otros tienen también, lo que él siente: lo "demoníaco" y lo "santo". " Y así como ha vaciado la visión pictórica en el recipiente interior de su alma, verbalmente se vacía, también, un vocablo en otro:

$$
\begin{aligned}
& \text { sensación que siento ...2 } \\
& \text { vivo... una vida...; }
\end{aligned}
$$

imagen y palabra están cumpliendo la misma faena

3.-Los ojos se han cansado de estar vueltos hacia dentro y regresan a la primera fase: hacia afuera. El esquema de la primera mostración

$$
\text { "este gran don Ramón... parece..., }
$$

ha sido alterado $y$, ahora, se hace

este gran don Ramón del Valle Inclán me inquieta.

Se han sumado la imagen - la figura del cuadro-con la comparación y con la sensación reflexiva, es decir, la mirada interior. Ya no tropezamos el nombre de pila, sino el apellido entero: aquello que no puede confundirlo con otro. Se trata, en este momento, tras la nominación entera, del poeta. Urge trasladarlo del lienzo pictórico al lienzo poético: versos actuales que, a manera de zona celeste -zodiaco-, buscan limitar10. El intento se esfuma, ${ }^{9}$ se extiende y propaga, como el carboncillo en el papel, por entre sus Obras: por eso, visiones de poetd. O, hecho ob. jeto vítreo - la intención busca otro recurso-, cae y se fracciona.

$$
\text { ...un fracaso de cristales }
$$

que son la manera de cada una de sus creaciones: sonoras.

7 Cfr. "Evocación", (v. 68 y 69):

y feliz quien al cielo se levanta [= la salvación, lo santo],

por las gradas de bierro de su infierno [=el pecado, lo demoniaco].

8 Hay un cierto gusto, en Dario, por los "acusativos internos": "soñar sueños", "ve... visión".

9 Obs, el "me" intensivo y demarcador, i.e. a mi que lo bago. 
4.-En este momento, el narrador regresa al escenario vivo del pasado; necesita ir hacia la vida; quiere guardar las distancias entre el cuadro, que está delante, y el recuerdo: lo histórico. Desea, también, darle una total movilidad y que actúe todo el cuerpo, como en los primeros versos actuó todo el rostro para formar la flor de su sonrisa. La movilidad atañe a una circunstancia en el tiempo y el narrador busca hacerla duradera:

Yo lo be visto arrancarse del pecbo la saeta..$^{10}$

la forma temporal - lo be visto- se hace intermitente y está apoyada por un presente durativo de reiteración:

le lanzan los siete pecados capitales.

Junto a viejo dios, altanero y esquivo - nota pagana- los siefe pecados capitales - lo demoníaco-, en forma de saeta, que don Ramón se arranca del pecho: arrepentimiento, visión católica.

¿Cuántas cosas no ha forzado Darío para cercar al "hombre Valle Inclán" y al "poeta Valle Inclán"? Uno y otro han huido, pero en el huir, en el esfumarse o en el romperse ha quedado un medallón poético: este mágico soneto. Las insinuaciones que de él se nos dan son "visiones de poeta", por ello, poesía hecha carne. En el museo de la Poesía quedará este retrato hecho por Darío: más hondo, más vivo, menos muerto que un cuadro pictórico, por el misterio de sus recursos y el aliento de sus palabras.

\section{S. Aguado-Andreut}

Universidad de Costa Rica, San José, Costa Rica.

10 Obs. que el dato histórico va acompañado de un "yo" insistente y afirmador, algo así como "yo y no otto lo he visto". 
